\title{
Process investigation and mechanical properties of electro sinter forged (ESF) titanium discs
}

\author{
Cannella, Emanuele; Nielsen, Chris Valentin; Bay, Niels
}

Published in:

International Journal of Advanced Manufacturing Technology

Link to article, DOI:

10.1007/s00170-019-03972-z

Publication date:

2019

Document Version

Peer reviewed version

Link back to DTU Orbit

Citation $(A P A)$ :

Cannella, E., Nielsen, C. V., \& Bay, N. (2019). Process investigation and mechanical properties of electro sinter forged (ESF) titanium discs. International Journal of Advanced Manufacturing Technology, 104(5-8), 1985-1998 . https://doi.org/10.1007/s00170-019-03972-z

\section{General rights}

Copyright and moral rights for the publications made accessible in the public portal are retained by the authors and/or other copyright owners and it is a condition of accessing publications that users recognise and abide by the legal requirements associated with these rights.

- Users may download and print one copy of any publication from the public portal for the purpose of private study or research.

- You may not further distribute the material or use it for any profit-making activity or commercial gain

- You may freely distribute the URL identifying the publication in the public portal 
1

2

\title{
Process investigation and mechanical properties of Electro Sinter Forged (ESF) titanium discs
}

\author{
Emanuele Cannella1,2,*, Chris Valentin Nielsen ${ }^{1}$, Niels Bay $^{1}$ \\ ${ }^{1}$ Technical University of Denmark, Department of Mechanical Engineering, \\ Produktionstorvet 425, Kgs. Lyngby DK-2800, Denmark \\ ${ }^{2}$ IPU, Diplomvej 376, Kgs. Lyngby DK-2800, Denmark \\ ${ }^{*}$ Corresponding author: cvni@mek.dtu.dk, +45 45254770, \\ Address: Produktionstorvet b425, DK-2800 Kgs. Lyngby, Denmark \\ ORCiD: i) 0000-0001-5628-8515, ii) 0000-0001-7774-4399, iii) 0000-0001-9560-6352
}

\begin{abstract}
Classified as an Electric Current Assisted Sintering (ECAS) process, Electro Sinter Forging (ESF) represents a sintering process following the resistance heating approach. The powder is simultaneously compacted and heated in a closed-die setup. The heating is generated by the Joule effect from the electrical current. Near net-shape components of conductive materials are made in the closed die-setup within a short process time (100-400 ms). The final relative density is an important quality measure for the sintered parts. In the present work, samples of commercially pure titanium are produced with up to $98 \%$ relative density by optimization of the main process parameters; namely electrical current density, compaction pressure and sintering time. Metallographic observations revealed that porosities were mostly found at the perimeter of the sintered samples. Mechanical testing by $\mu$-Vickers hardness test, uniaxial compression and indirect tensile tests showed improved properties of the material with increasing density. The achieved mechanical properties were compatible with the theoretical values for bulk titanium.
\end{abstract}

Electro Sinter Forging; Resistance sintering; Metal powder; Titanium; Metallography; Mechanical tests.

\section{Acknowledgements}

This research work was undertaken in the context of MICROMAN project ("Process Fingerprint for Zerodefect Net-shape MICROMANufacturing", http://www.microman.mek.dtu.dk/). MICROMAN is a European Training Network supported by Horizon 2020, the EU Framework Programme for Research and Innovation (Project ID: 674801).

\author{
Abbreviations \\ ASTM American Society for Testing and Materials International \\ bcc Body centered-cubic \\ BSD Backscattered detector \\ ECAS Electric Current Assisted Sintering \\ ESF Electro Sinter Forging \\ FAST Field Assisted Sintering Technology \\ GUM Guide to the expression of uncertainty in measurement \\ hcc Hexagonal close-packed
}


HP

HV

IDT

ISO

LOM

MFDC

SEM

SPS

Hot Pressing

Hardness Vickers

Indirect tensile test

International Organization for Standardization

Light optical microscopy

Middle-frequency direct current

Scanning electron microscope

Spark Plasma Sintering

\section{Introduction}

Sintering is a well-known manufacturing process enabling the production of components by starting from their powder state [1]. Ceramic and metal material can be manufactured. The process is traditionally divided into two main phases: i) powder compaction and ii) sintering in an oven. After the compaction, the "green body" is ejected and moved to a sintering oven. The main advantages related to sintering are the possibility of achieving near-net-shape components with complex geometries and the possibility of producing parts from materials only available in form of powder. The need for subsequent machining is minimal and often it is sufficient with grinding and polishing.

The processing time in conventional sintering is long as the sintering time in the oven can be in the order of one hour depending on the material. Variants of sintering processes have been developed in order to reduce the process time. Besides the production cycle, it is beneficial to minimize the time at which the sample stays at high temperature because of grain growth, creep phenomena and oxidation. To reduce the sintering time and temperature, a first improvement was represented by the Hot Pressing (HP) principle. Atkinson and Davies summarise the main characteristics of the HP process [2], where the green body is sintered inside the die while keeping a uniform pressure during the whole sintering time. The simultaneous action of the pressure and heating reduces the time and required temperature, enhancing the densification, limiting the grain growth and the use of sintering additives. The density is increased close to the theoretical value for silicon nitride specimens made by HP [3]. Particularly, they observe how the pressure with the liquid-phase produced by sintering is mostly effective in the first stages of sintering as a driving force to enhance the densification. However, further improvements were sought on the heating principle by changing from the traditional thermal transfer principle to the Joule heating principle. Kessel et al. summarise the main principles for such processes, described as directly based on the HP principle [4]. The main difference is the direct heating of the die and/or specimen provided by the flowing electrical current, which makes possible to increase the heating rate and have a more controlled sintering temperature. Several names were given to this process $[5,6]$, e.g. Electric Current Assisted Sintering (ECAS), Field Assisted Sintering Technology (FAST) and Spark Plasma Sintering (SPS) [7].

The Joule heat makes possible fast heating of the compact. The pressure is kept during the whole process to ensure optimal electrical contact between the electrodes and the sample. A complex electro-thermomechanical interaction realised, allowing fast densification in a reduced amount of time [8]. These differences are due to the different sintering mechanisms. The main driving forces in conventional sintering are based on the diffusional processes, governed by the reduction of the free-surface energy connected to the particle curvature [9]. The HP principle is based on the same diffusional processes as conventional sintering [2]. However, the applied pressure improves the diffusional paths by decreasing 
the residual porosity. The required energy is therefore lower than in the process without applied pressure. ECAS processes are governed by a different principle. The electrical current is flowing through the sample and/or the die. Vanmeensel et al. describe the effects of the current flowing through the sample, which generates interactions between the particles and the electrical field [10]. Electrical phenomena are therefore generated. Associated to mass transport, electromigration is considered the governing one. However, it is difficult to find its evidence in the lattice atoms because of scattering [10]. The dielectric breakdown involves surface cleaning phenomena at the particle surfaces [11]. Surfaces are cleaned from oxides and contaminants, therefore enhancing the process efficiency. Lastly, the electromagnetic pincheffect which causes powder shrinking in the radial direction [12]. The main effect is represented by an easier sample ejection because of the radial powder constriction. However, the density may be also affected by such constriction by closing pores.

Based on the electrical resistance principle, Fais developed the Electro Sinter Forging (ESF) process [13], which represents an application inside the ECAS world. In his research, he describes the main process characteristics. The used equipment is a capacitor discharge machine. A single electric impulse is combined with pressure for sintering of conductive powder. The pressure is controlled during the process. The electrical current in the ESF processes can be delivered as capacitor discharge, direct and alternate current. The load can be applied pneumatically or hydraulically and can be either constant or controlled and adjusted during the process. Several metal powders have been sintered by the ESF process. Forno et al. investigated the sintering of gold powder [14]. High-energy ball milling effects are investigated in terms of different achieved final properties. Fais et al. sintered nanocrystalline copper powder [15] and ironbased samples [16]. Hard metals were also investigated [17]. The main limitation of ESF is related to the electrical conductivity of the powder. Non-conductive powders cannot be sintered by ESF. Montes et al. sintered and analysed the mechanical properties of titanium samples by applying the electrical resistance principle [18]. A resistance welding machine was used, presumably running with alternate current. The specimens were sintered inside an electrically insulated die, made of alumina. A metallic hoop was used to strengthen the alumina core. The compaction pressure was kept during the whole process, ensuring good electrical contact between the tools and the sample. The main advantage is the short process time for sintering of the component. Less than one second is required to complete the sintering process [19]. The short time at which the part is at high temperature reduces the undesired effects at high temperature mentioned above. A deeper analysis would have involved a clear description of the process parameters and results concerning the compaction pressure variation. Furthermore, alternate current may give instability because of the profile nature of the current, where the high current peaks may melt the material.

In the present work, ESF is applied to make titanium discs. The main process parameters, electrical current density, sintering time and compaction pressure, were deeply investigated. The process was carried out on a direct current resistance welding machine and investigated by setting a short sintering time (100 $400 \mathrm{~ms})$, high electrical current (4-14 kA) and two different levels of pressure (97-188 MPa). A fully ceramic die was used to avoid electrical contact with the electrodes. The process parameters were optimized with respect to the final relative density of the sintered parts. The bonding mechanisms were investigated by analysis of micrographs made from the sintered parts. The final parts were also tested mechanically by $\mu$-Vickers hardness, uniaxial compressive and indirect tensile tests. The mechanical properties were compared to the bulk material properties of titanium. 


\section{Materials and experimental methods}

For experimental purposes, the sintered samples were disc-shaped. The disc geometry made possible to reduce all the influences determined by a complex geometry, e.g. thermal gradients and inhomogeneous compaction of the powder [20]. Each sintered disc is nominally $10 \mathrm{~mm}$ in diameter and $3 \mathrm{~mm}$ in thickness. An example is shown in Fig. 1. Commercially pure titanium powder, ASTM grade 2 and purity $99.7 \%$, (producer: GoodFellow) was used as a test material to test the process capability of ESF. According to the producer, the maximum particle size and bulk density were $150 \mu \mathrm{m}$ and $4.51 \mathrm{~g} / \mathrm{mm}^{3}$, respectively. The raw powder is shown in Fig. 2.

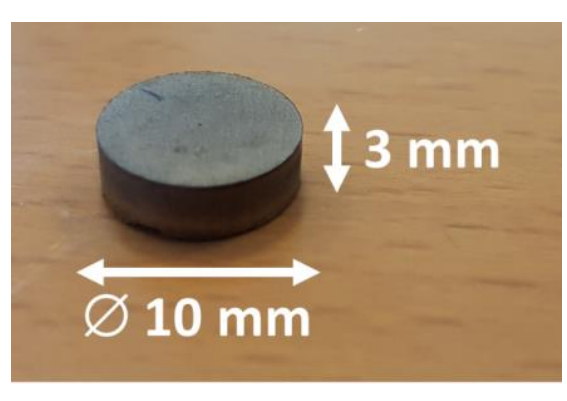

Fig. 1 Sintered disc-shaped sample

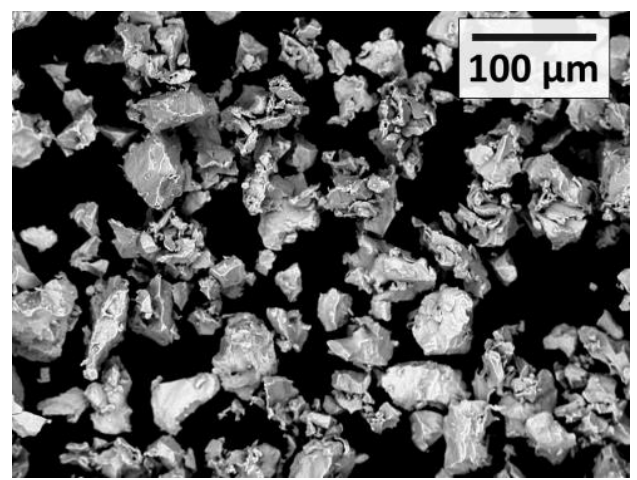

Fig. 2 SEM micrograph of the titanium particles

The sintering apparatus consisted of a middle-frequency direct current (MFDC) resistance welding machine (Expert 170kVA with Harms \& Wende HWI 2000 control unit) as shown in Fig. 3. It is mechanically operated by hydraulics and disc springs for follow-up of the force. The electrical current and load were monitored during the process by using a Rogowski coil and a load cell, respectively, as shown in Fig. 4 . The load cell was mounted inside a brass housing placed on the bottom of the tool setup. The measuring instruments were connected to a data acquisition system by National Instruments and monitored through a LabView interface. The die was entirely made with aluminium oxide $\left(\mathrm{Al}_{2} \mathrm{O}_{3} 99.7 \%\right.$ purity) in order to be electrically insulated and ensuring current flow through the powder. Conversely, the punches were made of electrolytic copper to be electrically conductive and acting as electrodes. The die was placed over the bottom punch and the top punch was aligned to the die after the powder was poured inside, see Fig. 5 . The powder was weighted with a measuring spoon $\left(0.5 \mathrm{~cm}^{3}\right)$ to have the same amount for each sample. 


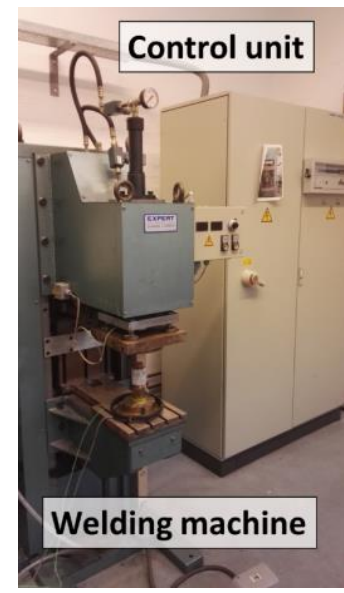

Fig. 3 Sintering apparatus

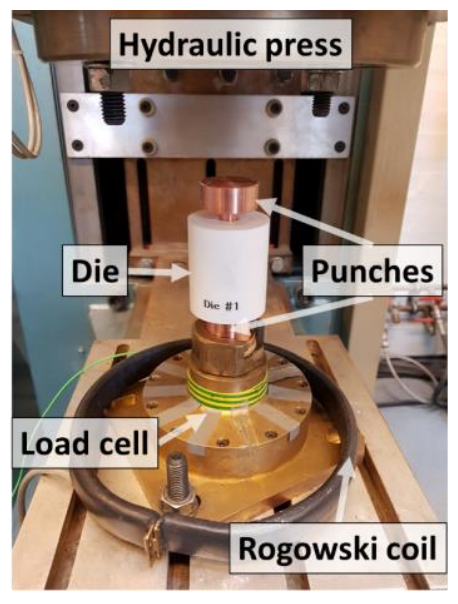

Fig. 4 Tool setup and measuring instruments used for sintering

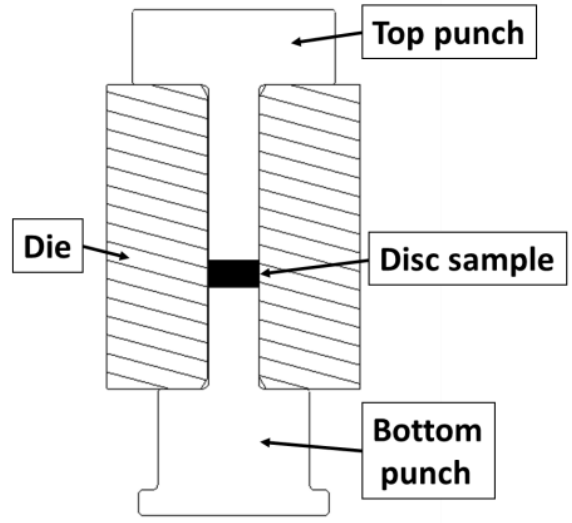

Fig. 5 Detail on the tool setup used for sintering

The die had an average roughness of $\mathrm{Ra}=0.54 \pm 0.24 \mu \mathrm{m}$ at the surface corresponding to the inner diameter. It was estimated by using a stylus roughness profilometer in the axial direction of the die. A good roughness tolerance is important to avoid damage to the sample while being ejected [21]. Recent work shows the influence of different sintering lubricants on the ejection force and roughness of the sintered part [22]. Zinc stearate was used for lubrication between the sample and the die. The sintering process was carried out in a normal air environment. After sintering, the discs were ejected by using a manual mechanical press. The density was estimated by measuring the weight of each sample with a precision balance (Sartorius Stedim Biotech $\mathrm{GmbH}$ ) and the volume by using 3D optical scanning technology (3Shape a/s), which allowed to build the 3D mesh of each sample. Two meshes were created for each sample (Fig. 6) and subsequently merged (Fig. 7) in MeshLab and analysed in software for dimensional analysis ( $\mathrm{GOM} \mathrm{GmbH}$ ) to obtain the volume. The present authors proved the compatibility of this method with the most common Archimedes' suspension method [23], commonly used for volume estimations [24]. 3D mesh made possible to avoid contaminations and liquid penetration caused by sample immersion.

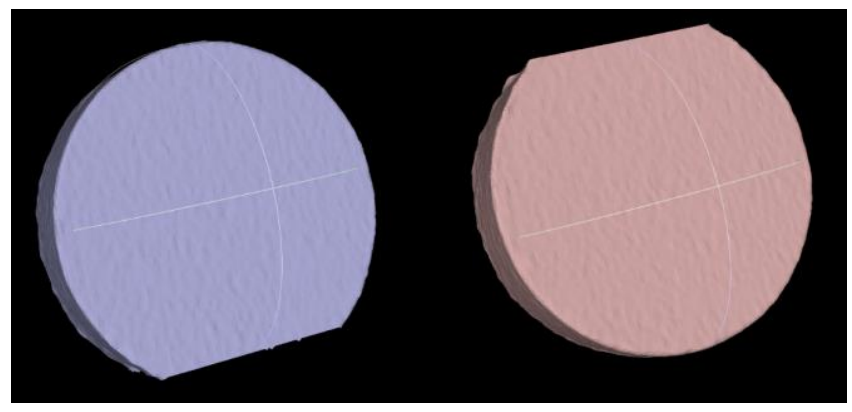

Fig. 6 Merging software operation with MeshLab

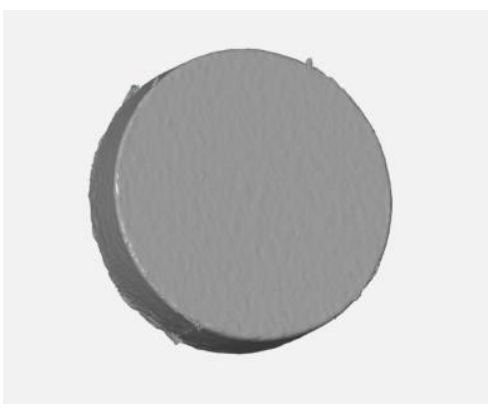

Fig. 7 Volume measurement in GOM

Metallographic preparation of the sample was made by cutting the samples at the diametrical section with a slow diamond saw. After moulding into epoxy resin, samples were prepared by grinding, polishing and etching. An optical microscope (Olympus LOM) was used for observation of the microstructures of 
the samples. Hardness tests were made on the same sample as prepared for microstructural observations with the Olympus microhardness tester FM-700. However, the analysis was made before the material etching to avoid any chemical and corrosion influence. Compression and indirect tensile tests shown in Fig. 8 were made in a 60 tons hydraulic Mohr \& Federhaff press.

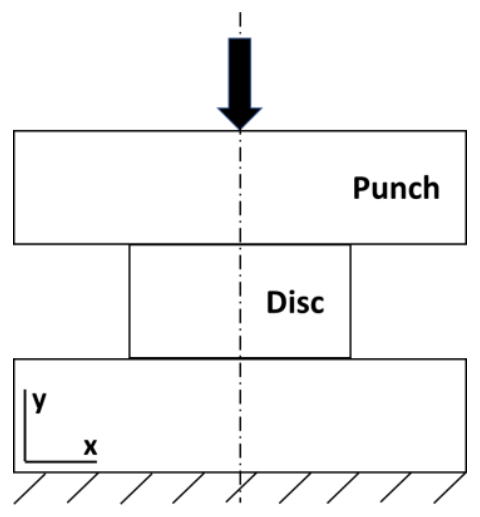

(a)

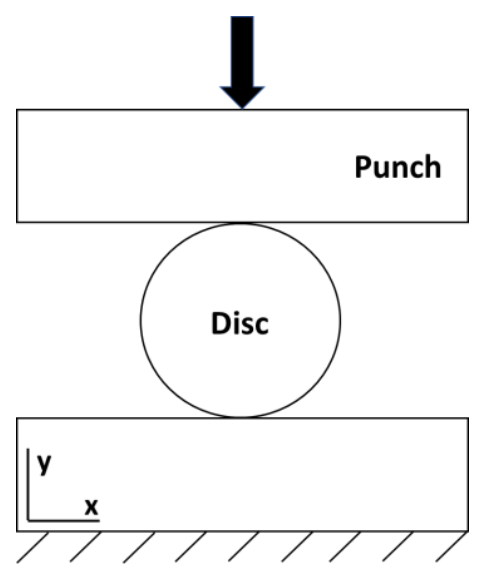

(b)

Fig. 8 (a) Uniaxial compression test and (b) indirect tensile test setups

\section{Experimental results}

\subsection{Influence of process parameters}

The investigation mainly consisted of establishing the working intervals for the main process parameters: compaction pressure, sintering time and electrical current density. The sintering time was kept in the range of $100-400 \mathrm{~ms}$. A typical process diagram is shown in Fig. 9. The largest electrical current density and compaction pressure used were $178 \mathrm{~A} / \mathrm{mm}^{2}$ and $188 \mathrm{MPa}$. The minimum and maximum values were established as a function of the machine and process limits. The obtained sample density was the evaluated performance property for each combination of process parameters. During the process, a slight deviation was noted because of the variations in the electrical and mechanical properties of the sintered sample. The compaction pressure varied $10-20 \mathrm{MPa}$ during sintering because of the softening during heating and lack of full follow-up from the hydraulic system (Fig. 9). This phenomenon is also stated by Fais [25]. If considering an average profile, the electrical current density had a decrease of $10-30 \mathrm{~A} / \mathrm{mm}^{2}$ due to the variation of the electrical resistance of the sample while sintering [26]. This is because the machine delivered the electrical current as a function of the electrical resistance and according to the nominal input value. 
Three series of experiments were made by varying the main process parameters, namely electrical current, pressure and time. Each parameter combination was replicated five times for the first series (electrical current), three times for the second and third series (pressure and time). The measurement uncertainty of the measured average for each parameter combination was estimated by considering the standard deviation and resolution of the instruments. The error propagation formula was applied and the coverage factor $k=2$ at a confidence level of $95 \%$ was assumed for the estimation of the expanded measurement uncertainty, according to the ISO GUM [27]. The relative density was estimated according to the bulk density of pure titanium, which corresponds to $4.51 \mathrm{~g} / \mathrm{cm}^{3}$ according to the producer (GoodFellow).

The electrical current density is the most influential process parameter because it influences the Joule heating with the power of two. Fig. 10 shows the relative density as a function of electrical current density. The parameter range corresponds to electrical currents of $4 \mathrm{kA}\left(\approx 51 \mathrm{~A} / \mathrm{mm}^{2}\right)$, which is the minimum the machine can deliver, $14 \mathrm{kA}\left(\approx 178 \mathrm{~A} / \mathrm{mm}^{2}\right)$, which was the maximum used because of the reduced effect on the relative density if increased further as seen in Fig. 10.

Two levels of pressure, $97 \mathrm{MPa}$ and $188 \mathrm{MPa}$, were tested. Lower values of pressure will result in too high electrical contact resistance between the green compact and the electrodes, which results in melting the sample and destroying the electrode surface because of dielectric breakdown. Additionally, high levels of compression are preferable because of better compaction and reduced starting porosity between the particles. Higher pressures were, however, not possible with the available hydraulic system of the welding machine. Fig. 11 shows that the pressure has a positive effect on the relative density, but also that the influence is less than the electrical current density. The relative density increased by less than $5.1 \%$ even when the compaction pressure was doubled.

The last series in Fig. 12 considered the variation of the sintering time by keeping the electrical current density and pressure constant. The increase in the final density is relevant when increasing from 100 to 
$200 \mathrm{~ms}$. Further increase of the sintering time did not increase the relative density but led to increased heating of the electrodes.

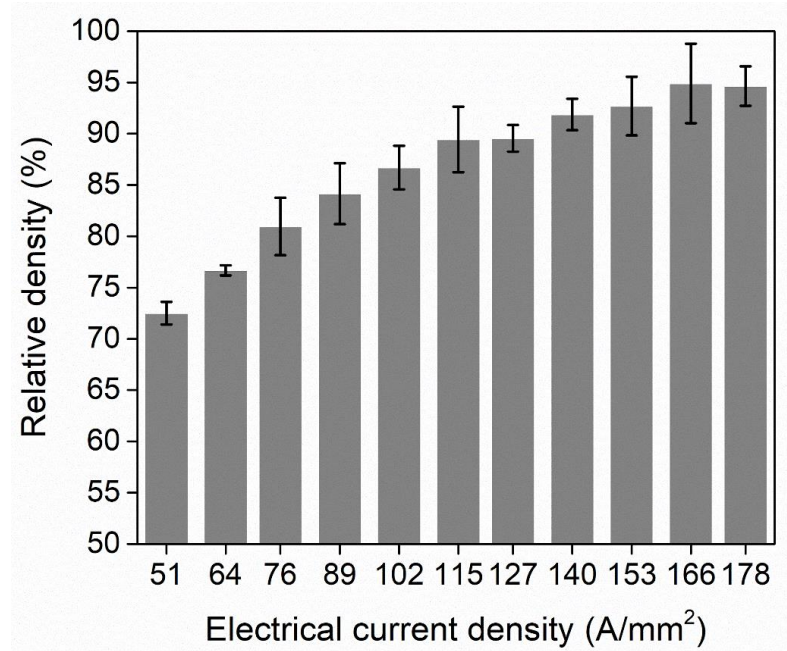

Fig. 10 Variation of the relative density as a function of the electrical current. Pressure and sintering time were kept constant, $169 \mathrm{MPa}$ and $150 \mathrm{~ms}$, respectively

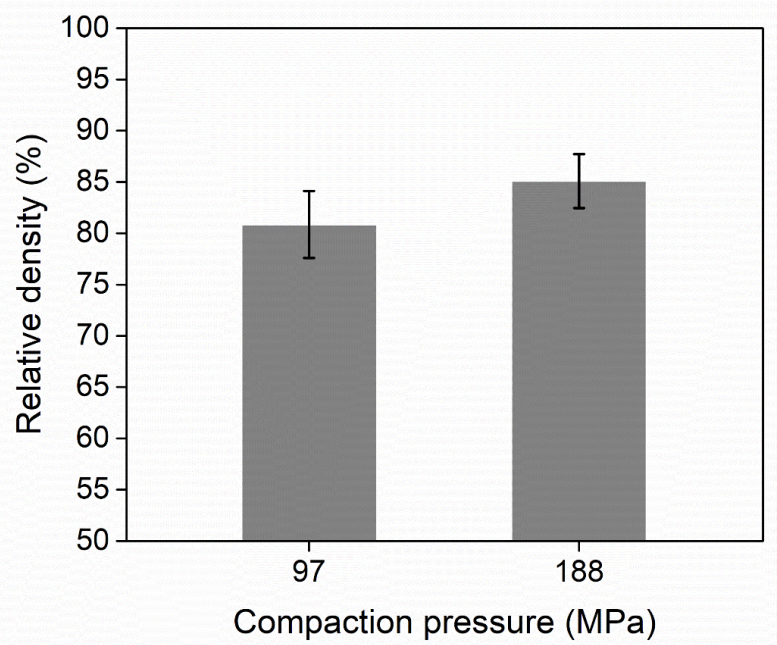

Fig. 11 Variation of the relative density as a function of the compaction pressure. Electrical current density and sintering time were kept constant, $102 \mathrm{~A} / \mathrm{mm}^{2}$ and $150 \mathrm{~ms}$, respectively

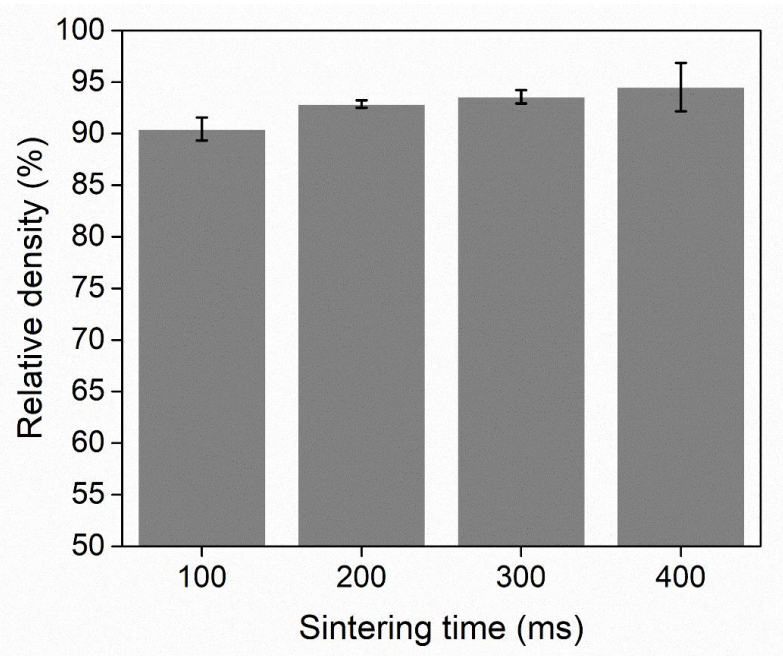

Fig. 12 Variation of the relative density as a function of the sintering time. Electrical current density and pressure were kept constant at $115 \mathrm{~A} / \mathrm{mm}^{2}$ and $169 \mathrm{MPa}$, respectively

\subsection{Micrograph investigations}

Micrographs were taken on different samples to analyse the obtained microstructures in terms of particle bounding and porosity distributions. The porosity concentration is large at the disc perimeter, while high density is achieved in the core; see Fig. 13. As described by Montes et al., a diametrical oval can be defined as the limit between the bulk and porous part [18]. This heterogeneous structure stems from the temperature gradient, which the samples were subjected to. The density estimations presented in Section 3.1 are average values. Fully dense samples could not be produced because of gasses trapped while 
compacting, which did not allow to close all pores. The samples sintered with larger values of electrical current showed a decrease of the porosity at the perimeter as seen in Fig. 13.

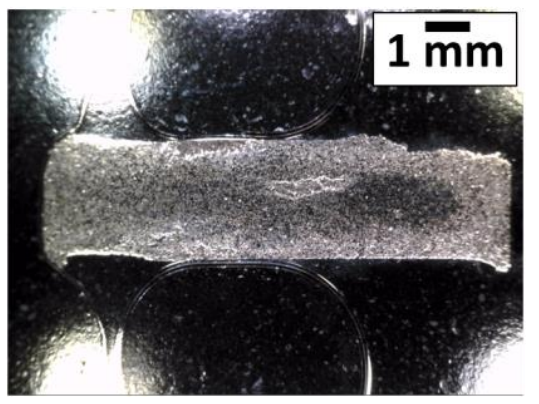

(a)

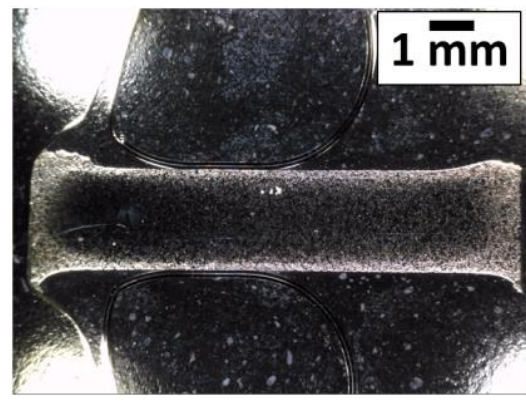

(b)

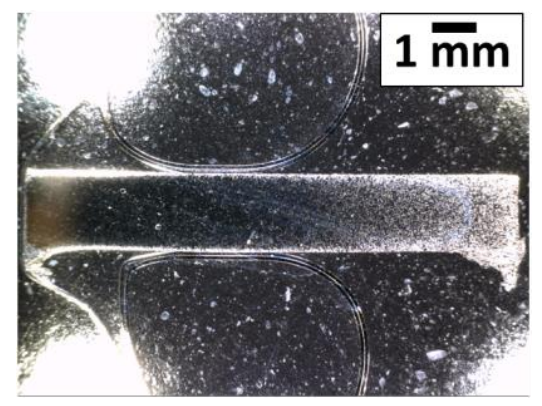

(c)

Fig. 13 (a) Sample sintered at $4 \mathrm{kA}\left(\approx 51 \mathrm{~A} / \mathrm{mm}^{2}\right)$, (b) at $9 \mathrm{kA},\left(\approx 115 \mathrm{~A} / \mathrm{mm}^{2}\right)$ and $(\mathrm{c})$ at $14 \mathrm{kA},\left(\approx 178 \mathrm{~A} / \mathrm{mm}^{2}\right)$. The compaction pressure was $169 \mathrm{MPa}$ and the sintering time was $150 \mathrm{~ms}$. The porosity at the perimeter decreased significantly for the highest current sample (c)

The micrographs in Fig. 14 are taken at the centre of selected samples to analyse the microstructure in the core. A clear correlation between the average relative density and the number of porosities in the core are seen when comparing Fig. 14a-c. Particle boundaries are visible in Fig. $14 d$, which is a magnification of Fig. 14a with a relative density of $72 \%$.

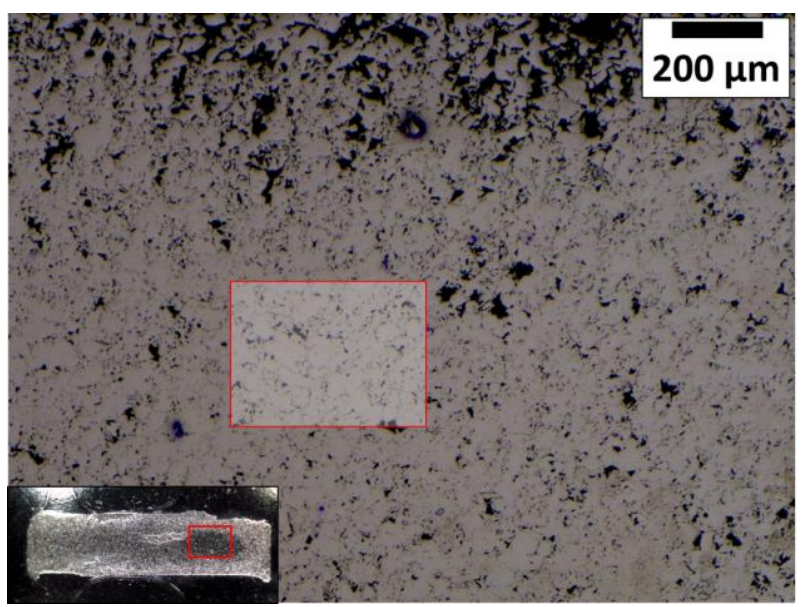

(a)

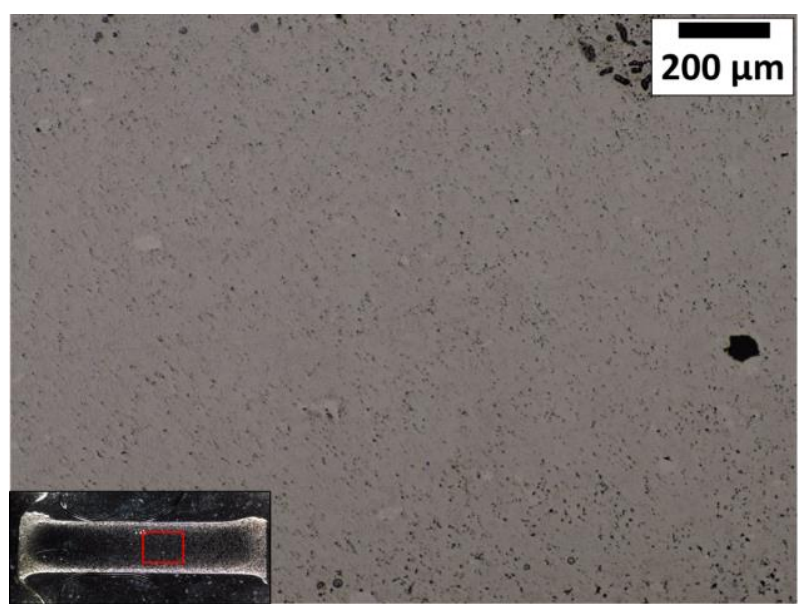

(b) 


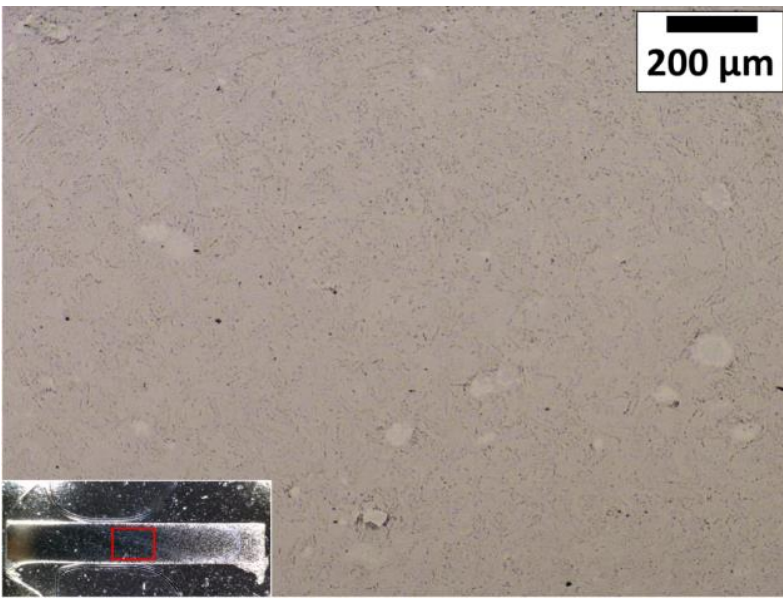

(c)

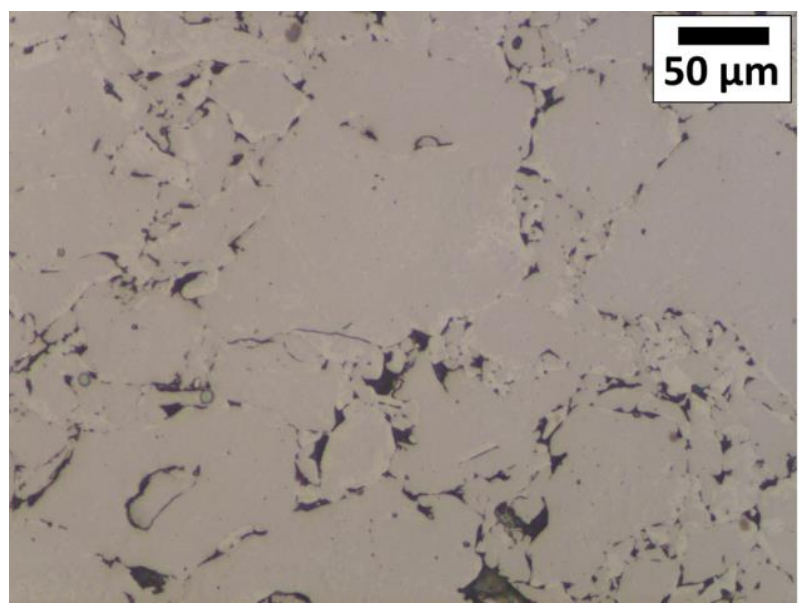

(d)

Fig. 14 Microstructure in the centre of selected samples with relative densities of (a) $72 \%$, (b) $89 \%$, (c) $98 \%$. A magnification of the sample with $72 \%$ relative density is shown in (d)

Kroll was used as the etching agent. As described in the literature [28], titanium is an allotropic material, which has two main crystallographic structures: i) hexagonal close-packed (hcp) at room temperature, namely alpha-phase and ii) body centered-cubic (bcc), namely beta-phase, when the material raises to the beta-transus temperature of $883^{\circ} \mathrm{C}$. This temperature is influenced by alpha- and beta-stabilizing elements, which increase or decrease the beta-transus temperature, respectively. The beta-phase is more ductile than the alpha-phase because of its bcc structure consisting of a larger number of slip planes. As shown in Fig. 15a, dark elements are distributed in the alpha-matrix. The lightest points are likely to be a secondary alpha-phase transformed from the beta-phase after cooling. Widmanstätten structures are visible as alpha-lamellae, generated from the sample cooling after sintering. The generation of those structures is explained by the high temperatures, which possibly were beyond the melting point. The melted material solidified and generated dendrites, similar to a casting process. The dark parts may indicate the beta-phase. The stabilising of such phase at room temperature can be explained by the presence of iron as an impurity in the starting powder [29]. As declared from the producer, up to $200 \mathrm{ppm}$ of iron was present inside the raw powder. Alternatively, the dark parts may represent TiC or oxides, resulting from the high temperatures. However, the role of the electrical current may have had an oxide dissolution role, as explained by Bonifacio et al. [11]. As shown in Fig. 15b, alpha lamellae were produced at some places, which is possibly due to melting and consequently diffusion free transformation. The same was seen in Fig. 17b for a lower electrical current density. Compared to Fig. 15a, Fig. 16a showed a more homogeneous matrix consisting of dark spots. The lower electrical current and consequently lower temperature could have helped in the structure homogenisation process. Further lowering of the current density led to the structure shown in Fig. 16b. No dark beta-spots are clearly visible in this case. Considering the ductile nature of beta-titanium compared to alpha-titanium, the material lost ductility in terms of elongation/height reduction, as will be observed in Section 3.4 describing mechanical properties. Fig. 17a shows characteristic large circle-shaped spots close to the perimeter in contrast to the homogenous matrix at the core. These spots may represent non-sintered particles due to the presence of 


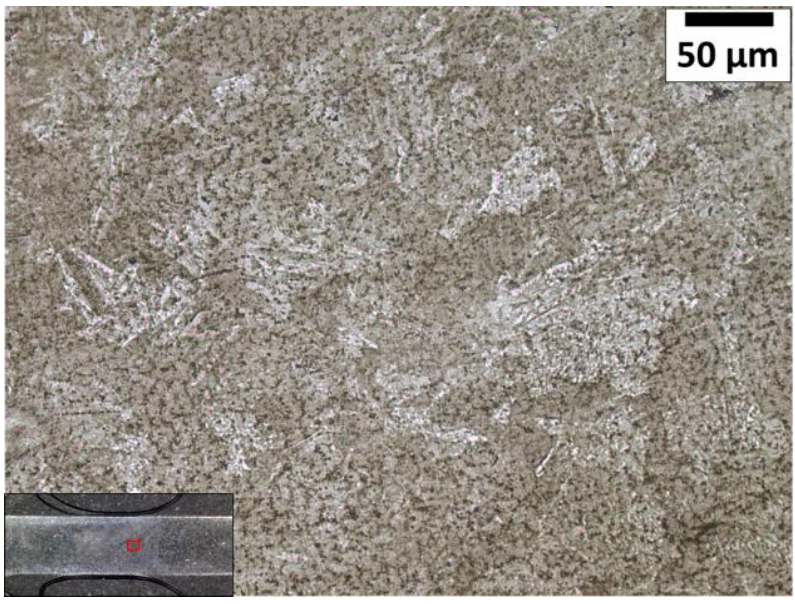

(a)

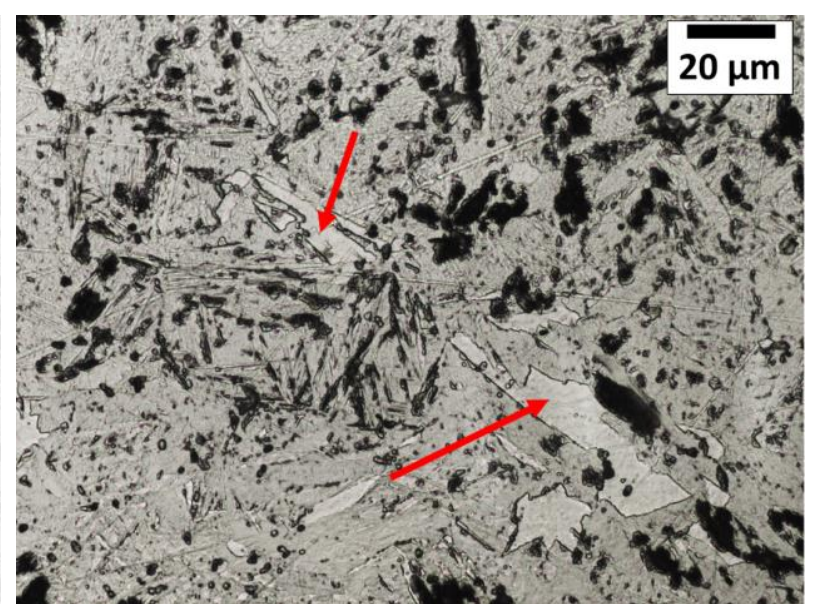

(b)

Fig. 15 Microstructures of titanium after being etched by using the Kroll's agent. The average relative density is $98 \%$ after sintering at $14 \mathrm{kA}\left(\approx 178 \mathrm{~A} / \mathrm{mm}^{2}\right)$ during $150 \mathrm{~ms}$ at a compaction pressure of 169 MPa. In (a), the lighter elements represent the alpha-phase, showing Widmanstätten structures. (b) Further magnification on the white spots shown in (a)

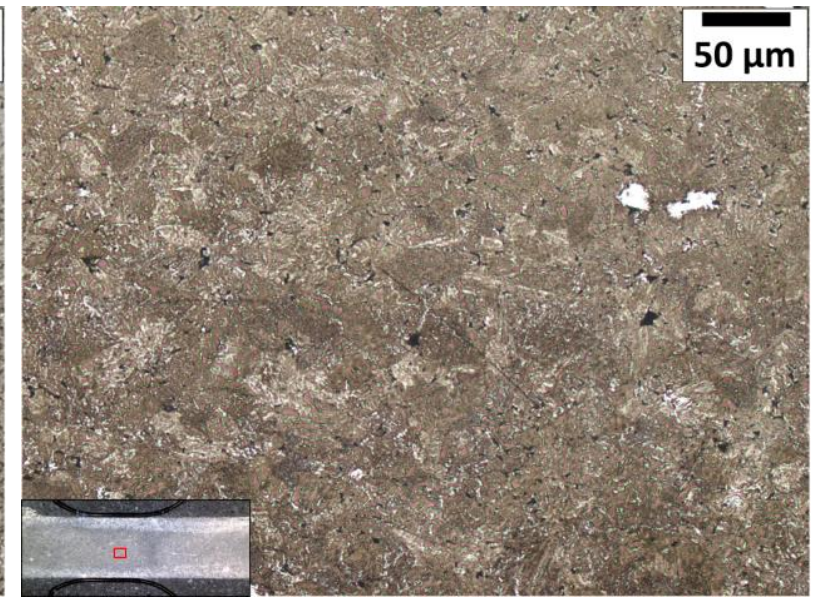

(b) 
Fig. 16 Microstructures obtained by sintering at (a) $13 \mathrm{kA}\left(\approx 166 \mathrm{~A} / \mathrm{mm}^{2}\right)$ resulting in $94 \%$ relative density and (b) $9 \mathrm{kA}\left(\approx 115 \mathrm{~A} / \mathrm{mm}^{2}\right)$ resulting in $89 \%$ relative density. Both are sintered during $150 \mathrm{~ms}$ with a compaction pressure of $169 \mathrm{MPa}$

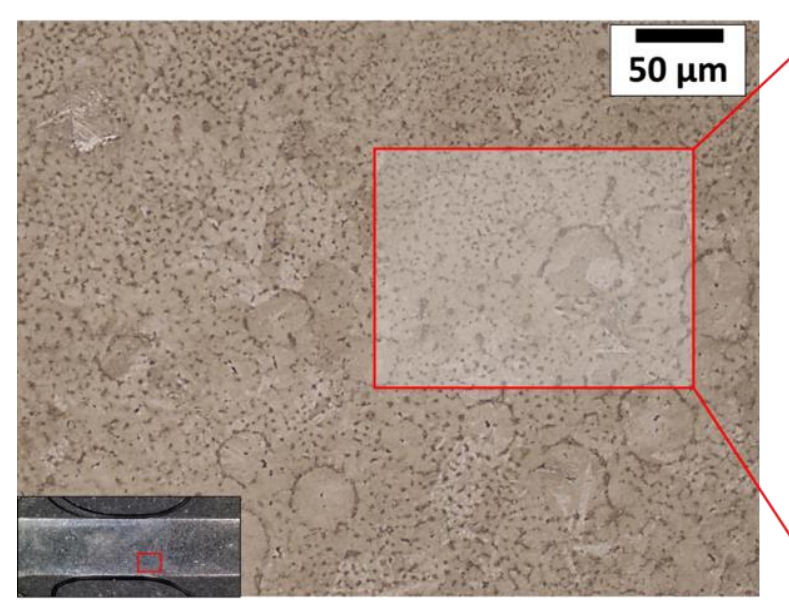

(a)

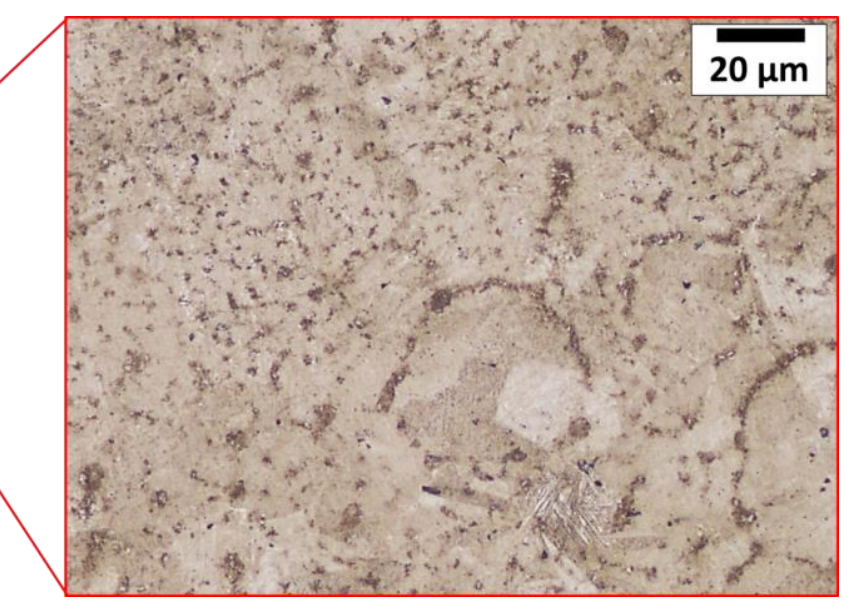

(b)

Fig. 17 Ti-disc sintered at $13 \mathrm{kA}\left(\approx 166 \mathrm{~A} / \mathrm{mm}^{2}\right), 150 \mathrm{~ms}$ and $169 \mathrm{MPa}$ resulting in $94 \%$ relative density. (a) Circle-shaped grains generated close to the perimeter of the section (bottom of the picture) as opposed to the finer structure in the core (top of the picture). (b) The detail on one of the round spots at the surface marked by the rectangle in (a)

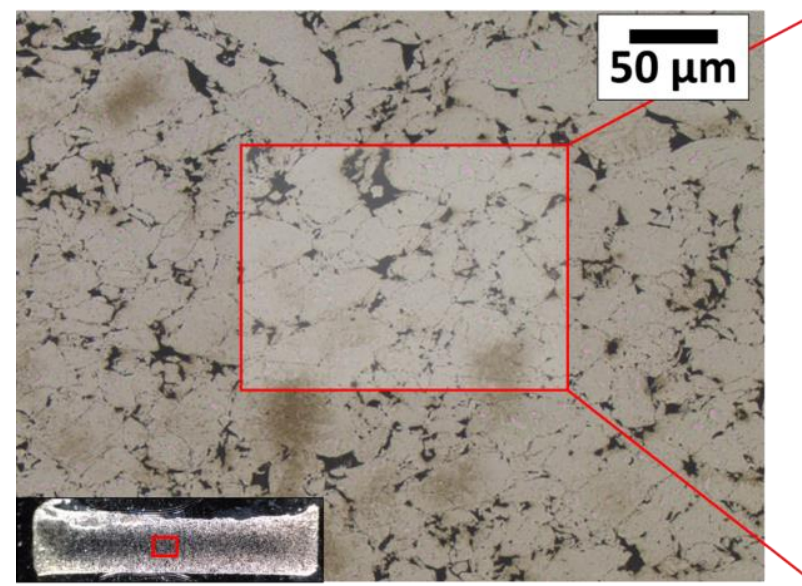

(a)

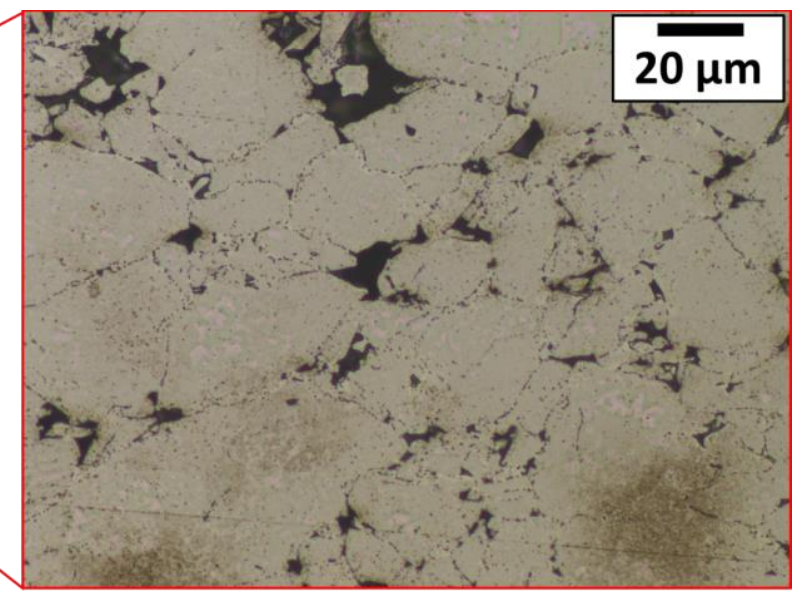

(b)

Fig. 18 Titanium disc sintered at $64 \mathrm{~A} / \mathrm{mm}^{2}(5 \mathrm{kA}), 350 \mathrm{~ms}$ and $169 \mathrm{MPa}$ resulting in $77 \%$ relative density. Boundaries are clearly visible, as suggested already in (b)

\subsection{Porosity distribution}

The analysis of the porosity was carried out to observe the pore distribution through the diametrical section of the different samples. The distribution was analysed by examining the optical micrographs before being chemically etched. The image processing software ImageJ was used to determine the 
amount of porosity in each measuring rectangular area of $0.2 \mathrm{~mm}$ by $1.5 \mathrm{~mm}$ enclosing around 400 by 1800 pixels, marked in red (Fig. 19). A smaller rectangular area than $3 \mathrm{~mm}$ was chosen and positioned in the middle of the disc height not to influence the results because of possible deviations from the nominal geometry, caused by worn tools and powder losses. The image was converted to binary and the porosity was therefore computed by counting the black (pore) and white (bulk) pixels. As shown in Fig. 19, the porosity estimation was done on 11 rectangular areas placed orthogonal to the diameter. There is $1 \mathrm{~mm}$ between each measurement area.

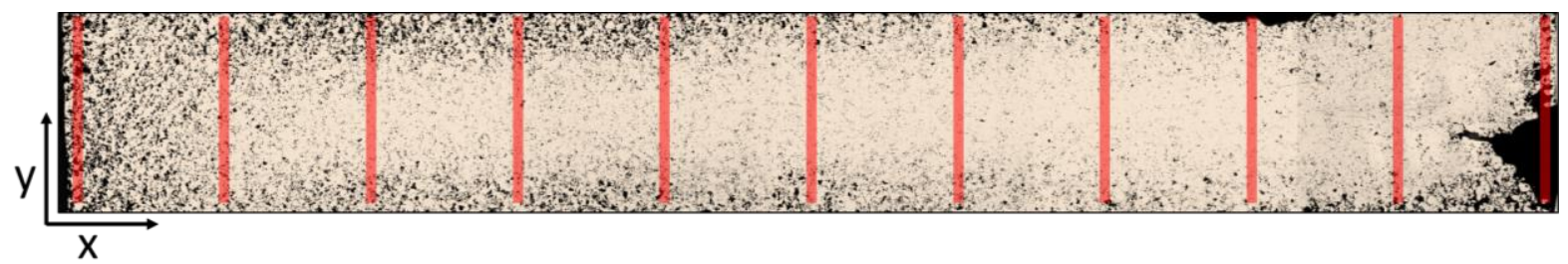

(a)

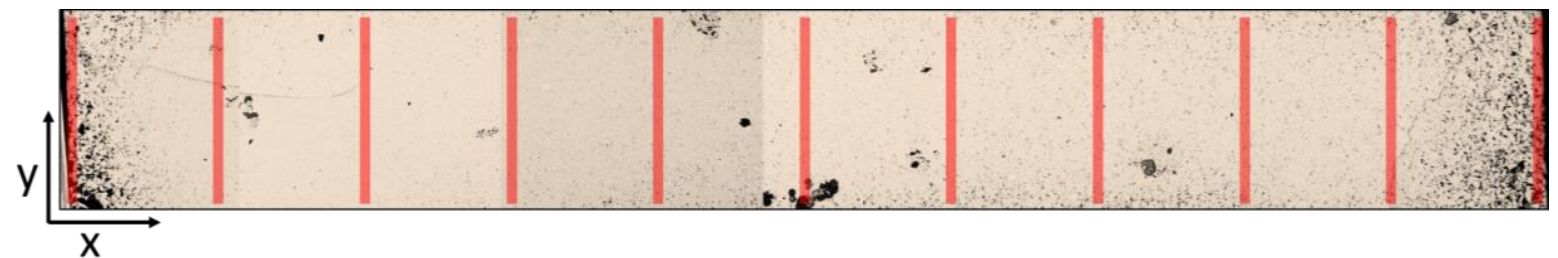

(b)

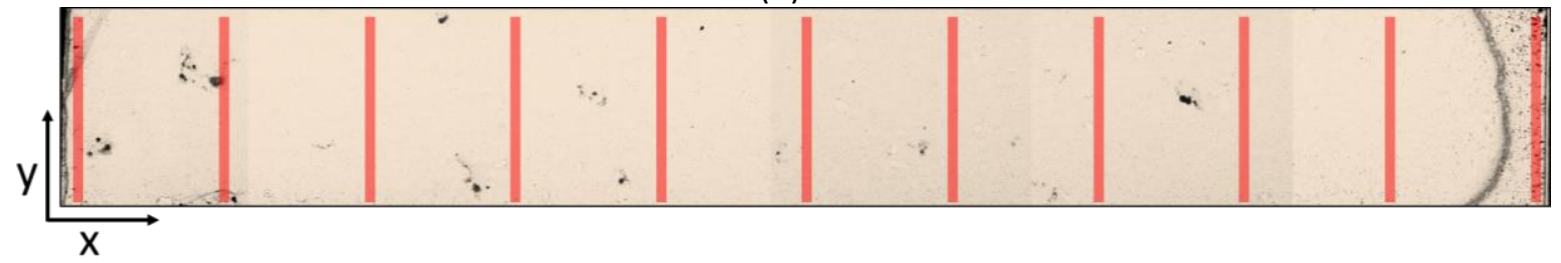

(c)

Fig. 19 Diametrical section of samples with relative densities of (a) $77 \%$, (b) $89 \%$ and (c) $98 \%$. Micrographs were converted into black and white to be further processed. The red lines with $1 \mathrm{~mm}$ spacing represent the measuring areas for the porosity estimation

For the largest relative densities, 89-98 \%, Fig. 20 shows a constant, high density with a low level of porosities from radius 0 to $4 \mathrm{~mm}$. The occurrence of melting resulted in low porosity in the core. Melting is justified by the high temperatures generally generated at the material core rather than at the end faces. Even if the temperature cannot be measured due to technological limits, numerical results proved this effect [30]. Significant porosity increase is only observed at the disc end faces in radius 4 to $5 \mathrm{~mm}$, which may be explained by the thermal gradient with the neighbouring tools or the clearance between the die and the sample causing a possible leak of powder and non-uniform compaction of the green body. If the electrode end faces in contact with the powder are properly aligned, non-uniform compaction is caused by the compaction process itself [31], leading to different density regions within the sample prior to sintering and thus causing different electrical resistance paths [32], resulting in different temperatures. Below a relative density of $80 \%$, the porosity distributions are quite heterogeneous, even with large values of porosities in the centre of the disc in some cases. The trapped air constituted an additional obstacle to sintering, generating oxides which negatively influenced the electrical flow. 
Fig. 20 Porosity estimation as a function of the radius for different sintered discs at different relative densities

The core SEM photo in Fig. 23a shows localised porosities at the particle boundaries in the case of samples sintered with low electrical current. Fig. 21b shows a SEM photo of a sample sintered with high electrical current. This fully dense core with round porosities is a result of melting and rapid solidification [33].

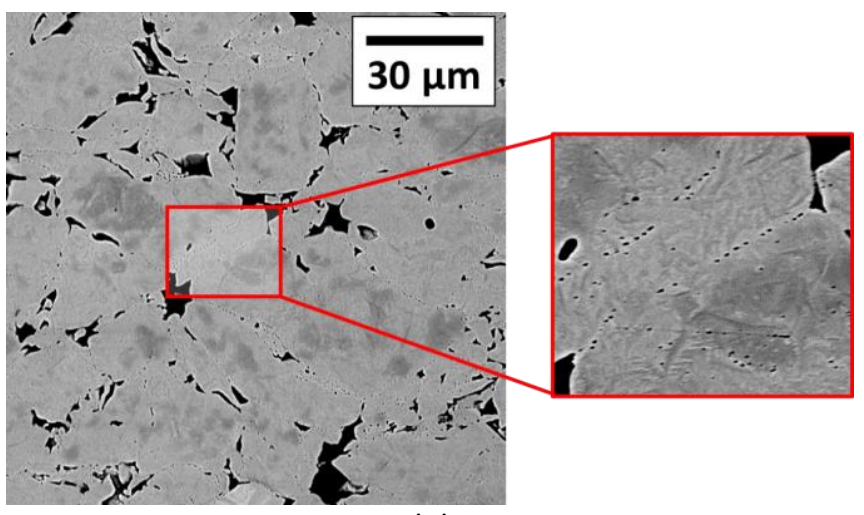

(a)

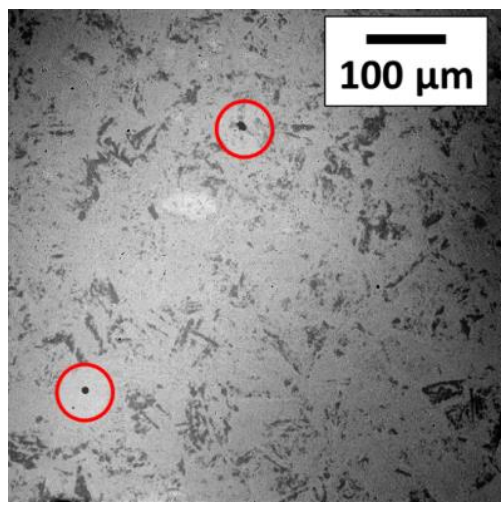

(b)

Fig. 21 SEM detail of the porous core sections for two different samples sintered at (a) $64 \mathrm{~A} / \mathrm{mm}^{2}$ in 350 $\mathrm{ms}$ and (b) $166 \mathrm{~A} / \mathrm{mm}^{2}$ in $150 \mathrm{~ms}$. The compaction pressure is $169 \mathrm{MPa}$ in both cases. For the low current, (a) shows porosities localized between particles and at their boundaries, as seen from the magnification. For the high current, (b) shows local round pores eventually caused by solidifying after melting, when air is trapped inside

\subsection{Mechanical tests, hardness measurements and weight loss}

Mechanical tests were done to establish a relation between the achieved densities and mechanical properties. Hardness, uniaxial compression and indirect tensile tests were performed.

The hardness measurements were made by applying the $\mu$-Vickers method according to the ISO 6507 standard [34]. The measuring procedure consisted of nine different indentations made at the core of the 
material after cutting the sample on a diametrical section and embedding in epoxy resin. The expanded measurement uncertainty was estimated from the standard deviation. A coverage factor $k=2$ at a confidence level of $95 \%$ was assumed according to the ISO GUM [27]. Each indentation was at least three diameters away from previous indents. The hardness estimation was made according to the Vickers method, which follows:

$$
H V=\frac{1854.4 L}{d^{2}}
$$

where $L$ is the applied load [g] and $d$ is the average diagonal [ $\mathrm{mm}$ ] resulting from the indentation. For this test, HV0.1 standard was applied (100 g) and 50x was used as optical lens. In total, five representative samples corresponding to different relative densities were investigated. As shown in Fig. 22, the hardness proved to be increased by larger density values. The different densities correspond to samples sintered by increasing electrical current and constant sintering time and compaction pressure. Above around $90 \%$ relative density the hardness stabilizes at $244 \pm 32 \mathrm{HV} 0.1$. The hardness for the annealed titanium ASTM grade 2 is found to be 200 HB [35], which corresponds to about 211 HV0.1. Possible appearance of betaspots (Fig. 22) may explain the hardness increase because of the harder nature of this phase [36]. Furthermore, it has to be considered that the compacting and sintering process plastically deformed the powder particles, which changes the original shape and strain hardens the particles. The increase of the yield strength led to a larger hardness [37]. Conversely, a low current (resulting in $72 \%$ relative density) gave rise to a low hardness of only $77 \pm 32 \mathrm{HV} 0.1$. This is mostly due to the low density and weak cohesion of powder particles [38]. In both cases, the average dispersion was found to be $\pm 32 \mathrm{HVO}$.1. This is due to the heterogeneity of the structure and indentations which were randomly made at the core of the particle or close to its boundaries.

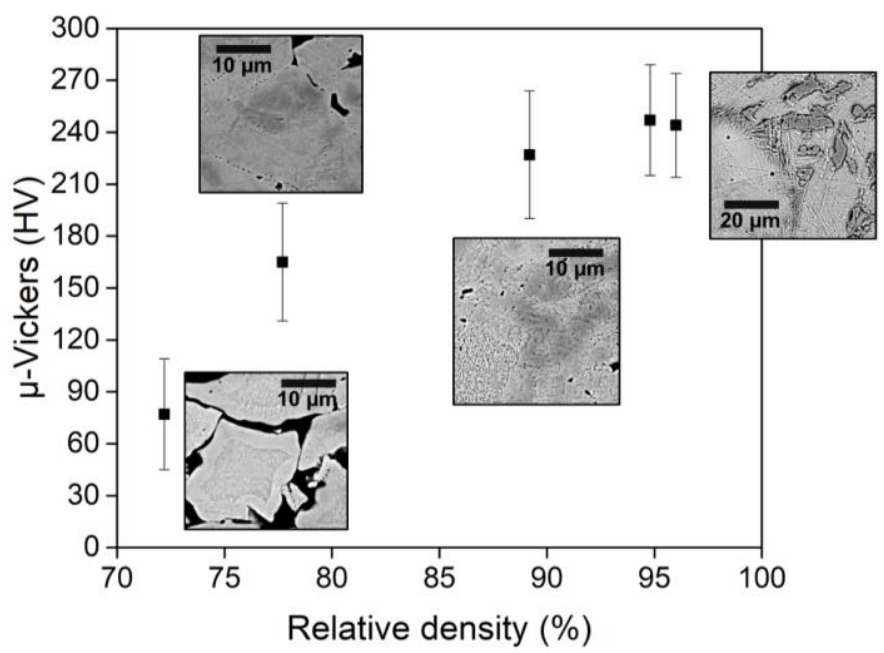

Fig. 22 Hardness measurements as a function of different relative densities for the sintered titanium. Pictures taken with BSD electron microscopy show the microstructure changes influencing the measured hardness

Uniaxial compression tests were performed with molybdenum disulphide to reduce friction between the tool and the samples. The test was carried out by applying a maximum load of $370 \mathrm{kN}$. The thickness was 
reduced by approximately $50 \%$. The samples with the lowest densities in Fig. 23a, b were most affected and showed cracks and a non-uniform circular shape after compression. Conversely, no visible cracks were observed in the samples with high density as shown in Fig. 23c, d. In Fig. 24 it is shown that the weight losses of the samples range from 5 to $23 \%$. This weight loss stems from material lost from the porous end faces, and therefore, the most porous samples lose more mass. More uniform samples with high relative density had less mass loss and deformed more homogeneously.

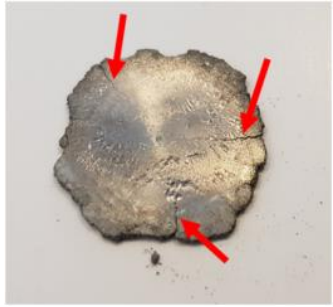

(a)

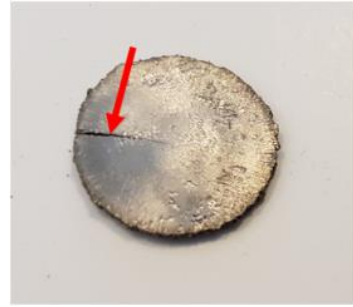

(b)

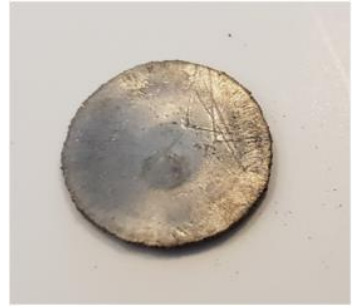

(c)

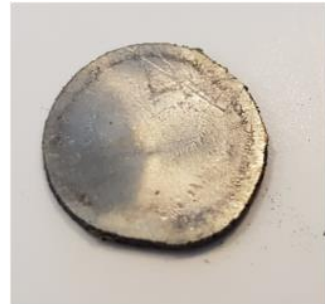

(d)

Fig. 23 Samples after uniaxial compression testing. The initial relative densities of the samples were (a) $72.0 \%$, (b) $86.6 \%$, (c) $90.3 \%$ and (d) $96.0 \%$. Red arrows indicate the presence of cracks

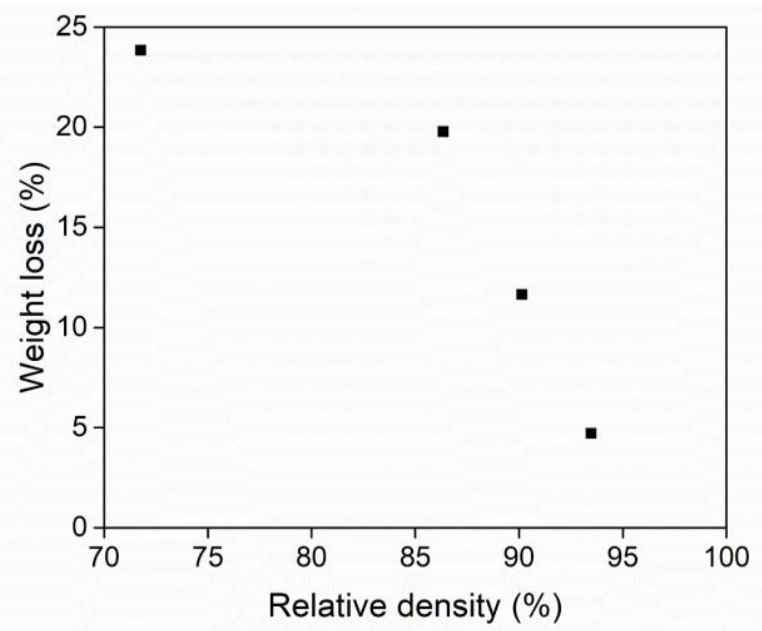

Fig. 24 Weight loss during compression testing as a function of the initial relative density of the samples

Tensile properties were tested by compressing the sintered specimens via the indirect tensile test (IDT) approach [39]. In this test, a diagonal compression of the sample is carried out as shown in Fig. 8b. Tensile stresses develop perpendicular to the loading direction and the indirect tensile stress (IDT) at fracture is estimated as follows:

$$
\sigma_{I D T}=\frac{2 P}{\pi D t}
$$

where $P$ is the maximum achieved load, $D$ and t are the starting disc diameter and thickness, respectively. Results were analysed as a function of the different starting relative densities. However, the compressed specimens exhibited two different fracture behaviours, namely brittle and ductile. Specimens below $80 \%$ relative density showed a fracture parallel to the loading direction (Fig. 25a, b). Specimens with a relative 
density larger than $80 \%$ broke in a direction perpendicular to the loading direction. Presumably, this was due to a ductile fracture, caused by plastic deformation along the horizontal direction at high compressive loads (Fig. 25c-f). This was mostly seen in Fig. 25e, f, where the shiny appearance is due to the high plastic deformation causing fracture, typical of a ductile one. The IDT is valid for elastic deformation until brittle fracture. Procopio et al. showed that for ductile fractures, the analytical $\sigma_{\text {IDT }}$ value underestimates the actual value by a factor of $2.5-3$ since plasticity and strain hardening are not accounted for [40]. Fig. 26 shows the maximum load under diametrical compression with the identification of the two fracture types while Fig. 27 shows the estimated $\sigma_{\text {IDT }}$.

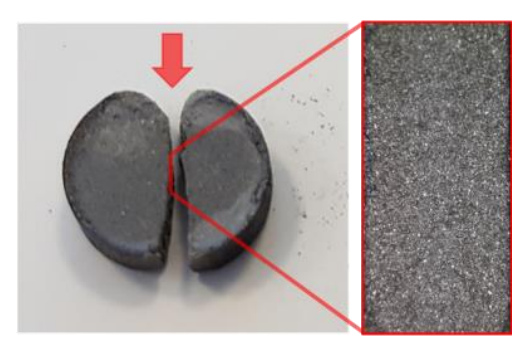

(a)

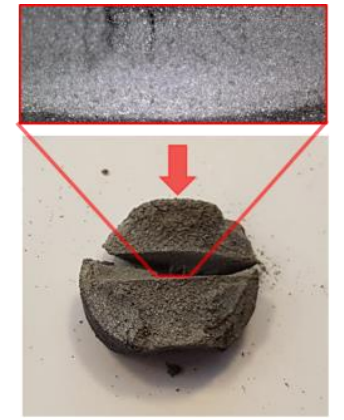

(d)

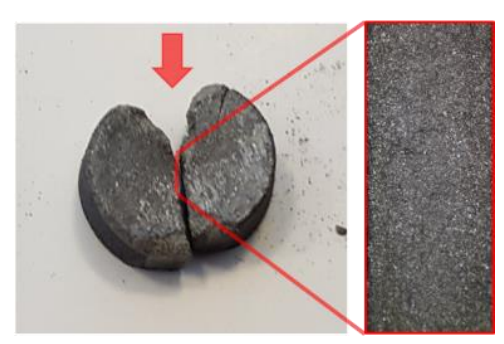

(b)

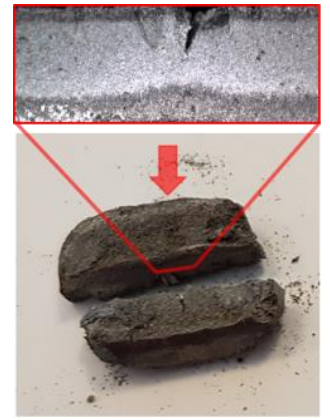

(e)

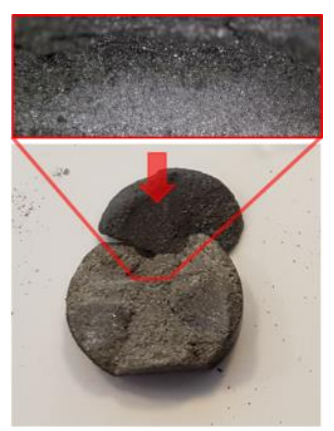

(c)

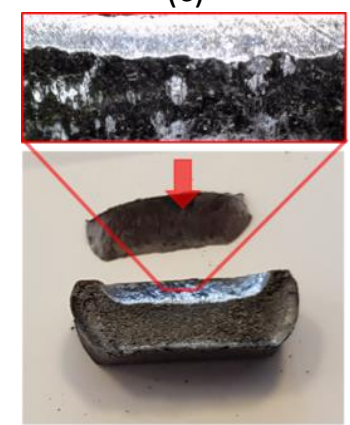

(f)

Fig. 25 Different samples after being loaded in the IDT setup. Different fracture types were obtained as a function of the relative density: (a) $73 \%$, (b) $77 \%$, (c) $81 \%$, (d) $86 \%$, (e) $91 \%$, (f) $96 \%$. The arrows indicate the compression direction 


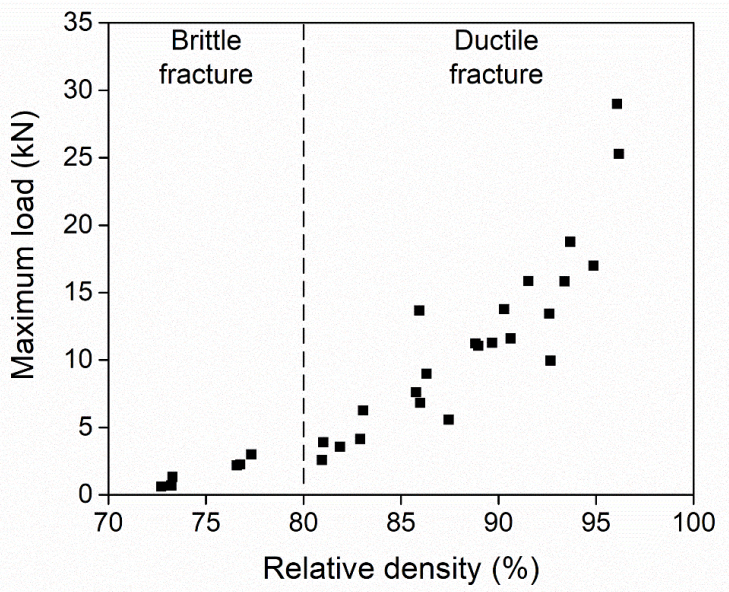

Fig. 26 Measured maximum load in the diametrical compression test as a function of different relative densities. The dashed line identifies the change of the fracture type

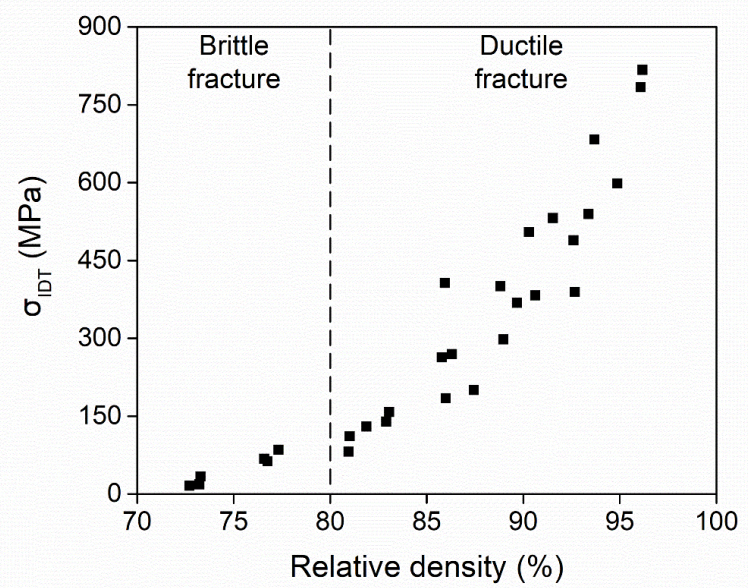

Fig. 27 Tensile stress estimated after IDT. Results from samples with ductile fracture could be underestimated due to the $\sigma_{I D T}$ not accounting for strain hardening and plasticity

The ductile samples could be reduced more than $50 \%$ of its diameter before fracturing. This increase in strength and ductility agreed with the observations made on the micrographs, which showed small spots of the more ductile beta-phase inside the alpha-matrix. Furthermore, the larger softening obtained with high temperatures may have increased the plastic deformation during sintering. This would have led to an increased yield strength due to strain hardening.

\section{Conclusions and outlook}

Samples from commercially pure titanium powder, ASTM grade 2, were successfully sintered in a resistance welding machine under various process parameters. The sintered shape was a disc with $10 \mathrm{~mm}$ diameter and $3 \mathrm{~mm}$ thickness. The process parameters analysed were the electrical current density (51 $\left.178 \mathrm{~A} / \mathrm{mm}^{2}\right)$, the compaction pressure $(97-188 \mathrm{MPa}$ ) and the sintering time (100-400 ms). The influence of the process parameters was analysed by considering one variable at a time. The analysed output was the final sample density, which was compared to the bulk one for pure titanium. The electrical current density showed the largest influence. Good repeatability of results was obtained, showing also the possibility of having a controlled density for the sintered samples. This may be taken into account when sintering components with a desired final porosity such as in medical prosthesis. The highest relative density obtained was $98 \%$. To evaluate the mechanical properties of the sintered samples, several mechanical tests were performed; namely $\mu$-Vickers hardness tests, indirect tensile test and uniaxial compression test. The hardness increased with increasing relative density and stabilised above $90 \%$ relative density. Regarding the indirect tensile test (IDT), samples were found to have an exponential increasing load at fracture with increasing relative density. The fracture type changed from brittle to ductile when passing around $80 \%$ relative density. The uniaxial compression revealed a weight reduction by lost pieces of the samples, which was more severe for the brittle samples with lower relative density. This highlighted a double behaviour in terms of ductile deformation at the core and brittleness corresponding to the porous part at the perimeter. Furthermore, a porosity characterisation was done along the diameter. It was proven that the samples with high relative density are more homogeneous in 
terms of porosity distribution. Local porosities at the particle boundaries were observed for low density samples.

The metallographic analysis showed the bonding mechanism and porosities of the samples resulting from different process parameters. Particle boundaries were mostly visible for samples with low relative densities, where the particle deformation and bonding to neighbouring particles were visible. At high relative densities, chemical etching made it possible to observe the generation of alpha- and beta-phases of titanium. The beta-phase is generated above the beta-transus temperature. The presence of beta was explained by the presence of beta-stabiliser impurities, i.e. iron, and large thermal gradients and cooling generating retained beta. This eventually proved the increased tensile strength of the samples, as density increased. Secondary alpha spots were also observed, mostly caused by beta to alpha diffusion free transformations. Microstructure heterogeneities gave information on how the temperature was distributed during sintering.

Future work will involve other conductive powders for other potential applications. Optimal process parameters will be different due to the different thermal and electrically conductive properties. Other sample sizes and different shapes are also of interest in order to understand the possible limits of the process. Changing the sample size will change the thermal gradients and therefore the relative amount of heterogeneities stemming from cooling from the die and electrodes. On the application side, small gears to be used in mechanical systems, e.g. watches, or magnetic rings to be used as rotors, e.g. in small electric engines, could be thought to be sintered and mechanically tested. Functional tests could follow to check their applicability.

\section{References}

1. Castro RHR (2013) Sintering. Springer Berlin Heidelberg, Berlin, Heidelberg

2. Atkinson H V., Davies S (2000) Fundamental aspects of hot isostatic pressing: An overview. Metall Mater Trans A Phys Metall Mater Sci 31:2981-3000. https://doi.org/10.1007/s11661-000-0078-2

3. Bhandhubanyong $P$, Akhadejdamrong $T$ (1997) Forming of silicon nitride by the HIP process. J Mater Process Technol 63:277-280. https://doi.org/10.1016/S0924-0136(96)02635-0

4. Kessel HU, Hennicke J, Schmidt J, et al (2008) " FAST " field assisted sintering technology- a new process for the production of metallic and ceramic sintering materials

5. Grasso S, Sakka Y, Maizza G (2009) Electric current activated/assisted sintering ( ECAS ): a review of patents 1906-2008. Sci Technol Adv Mater 10:053001. https://doi.org/10.1088/1468$6996 / 10 / 5 / 053001$

6. Anselmi-Tamburini U, Groza JR (2017) Critical assessment: electrical field/current application-a revolution in materials processing/sintering? Mater Sci Technol (United Kingdom) 33:1855-1862. https://doi.org/10.1080/02670836.2017.1341692

7. Hitchcock D, Livingston R, Liebenberg D (2015) Improved understanding of the spark plasma sintering process. J Appl Phys 117:1-6. https://doi.org/10.1063/1.4919814

8. Guillon O, Gonzalez-Julian J, Dargatz B, et al (2014) Field-Assisted Sintering Technology/Spark Plasma Sintering: Mechanisms, Materials, and Technology Developments. Adv Eng Mater 16:830849. https://doi.org/10.1002/adem.201300409

9. Dong Z, Zhang J, Li S, et al (2015) Sintering and Densification (I)-Conventional Sintering Technologies. In: Optical Materials. pp 291-394

10. Vanmeensel K, Laptev A, Huang SG, et al (2012) The Role of the Electric Current and Field during 
Pulsed Electric Current Sintering. In: Ceramics and Composites Processing Methods. John Wiley \& Sons, Inc., Hoboken, NJ, USA, pp 43-73

11. Bonifacio CS, Holland TB, van Benthem K (2013) Evidence of surface cleaning during electric field assisted sintering. Scr Mater 69:769-772. https://doi.org/10.1016/j.scriptamat.2013.08.018

12. Yurlova MS, Demenyuk VD, Lebedeva LY, et al (2014) Electric pulse consolidation: An alternative to spark plasma sintering. J Mater Sci 49:952-985. https://doi.org/10.1007/s10853-013-7805-8

13. Fais A (2010) Processing characteristics and parameters in capacitor discharge sintering. J Mater Process Technol 210:2223-2230. https://doi.org/10.1016/j.jmatprotec.2010.08.009

14. Forno I, Actis Grande M, Fais A (2015) On the application of Electro-sinter-forging to the sintering of high-karatage gold powders. Gold Bull 48:127-133. https://doi.org/10.1007/s13404-015-0169$x$

15. Fais A, Leoni M, Scardi P (2012) Fast Sintering of Nanocrystalline Copper. Metall Mater Trans A 43:1517-1521. https://doi.org/10.1007/s11661-011-0727-7

16. Fais A, Actis Grande M, Forno I (2016) Influence of processing parameters on the mechanical properties of Electro-Sinter-Forged iron based powders. Mater Des 93:458-466. https://doi.org/10.1016/j.matdes.2015.12.142

17. Lagos MA, Agote I, Schubert T, et al (2017) Development of electric resistance sintering process for the fabrication of hard metals: Processing, microstructure and mechanical properties. Int J Refract Met Hard Mater 66:88-94. https://doi.org/10.1016/j.ijrmhm.2017.03.005

18. Montes JM, Rodríguez JA, Cuevas FG, Cintas J (2011) Consolidation by electrical resistance sintering of Ti powder. J Mater Sci 46:5197-5207. https://doi.org/10.1007/s10853-011-5456-1

19. Yu M, Grasso S, Mckinnon R, et al (2017) Review of flash sintering: materials, mechanisms and modelling. Adv Appl Ceram 116:24-60. https://doi.org/10.1080/17436753.2016.1251051

20. Grigoryev EG, Olevsky EA (2012) Thermal processes during high-voltage electric discharge consolidation of powder materials. Scr Mater 66:662-665. https://doi.org/10.1016/j.scriptamat.2012.01.035

21. Solimanjad N, Larsson M (2005) Tribological properties of lubricants used in PM process. In: Euro Pm 2005: Powder Metallurgy Congress and Exhibition. European Powder Metallurgy Association (EPMA), pp 123-131

22. Cannella E, Nielsen CV (2018) Lubricant Influence on the Ejection and Roughness of In-Die Electro Sinter Forged Ti-Discs. Key Eng Mater 767:171-178. https://doi.org/10.4028/www.scientific.net/KEM.767.171

23. Cannella E, Nielsen CV, Bay N (2018) Process parameter influence on Electro-sinter-forging (ESF) of titanium discs. In: 18th Int. Conf. EUr. Soc. Precis. Eng. Nanotechnology, EUSPEN 2018. euspen, pp 315-316

24. ASTM International (2013) Standard Test Methods for Density of Compacted or Sintered Powder Metallurgy (PM) Products Using Archimedes' Principle. Astm B962-13 i:1-7. https://doi.org/10.1520/B0962-13.2

25. Fais A (2018) A faster FAST: Electro-Sinter-Forging. Met Powder Rep 73:80-86. https://doi.org/10.1016/j.mprp.2017.06.001

26. Montes JM, Cuevas FG, Cintas J, Urban P (2011) Electrical conductivity of metal powders under pressure. Appl Phys A Mater Sci Process 105:935-947. https://doi.org/10.1007/s00339-011-65159

27. ISO/IEC (2008) Guide 98-3: 2008 Uncertainty of measurement -- Part 3: Guide to the expression of uncertainty in measurement (GUM:1995). https://www.iso.org/standard/50461.html. Accessed 5 May 2017

28. Gammon LM, Briggs RD, Packard JM, et al (2004) Metallography and Microstructures of Titanium and its Alloys. Mater Park OH ASM Int 2004 9:899-917. https://doi.org/10.1361/asmhba0003779 
29. Yan M, Luo SD, Schaffer GB, Qian M (2013) Impurity (Fe, Cl, and P)-induced grain boundary and secondary phases in commercially pure titanium (CP-Ti). Metall Mater Trans A Phys Metall Mater Sci 44:3961-3969. https://doi.org/10.1007/s11661-013-1720-0

30. Olevsky EA, Dudina D V. (2018) Resistance Sintering. Springer International Publishing, Cham

31. Höganäs $A B$ (2013) Production of sintered components. Höganäs $A B$ 1:170

32. Montes JM, Cuevas FG, Cintas J (2011) Electrical resistivity of a titanium powder mass. Granul Matter 13:439-446. https://doi.org/10.1007/s10035-010-0246-z

33. Foundry Lexicon (2018) Microporosity. https://www.giessereilexikon.com/en/foundrylexicon/Encyclopedia/show/microporosity-3953/?cHash=dc19bc24c4de598f06f1e1167ba2b379.

Accessed 26 Apr 2018

34. ISO (2018) BS EN 6507-1:2018 - Metallic materials - Vickers hardness test - Part 1: Test method. https://www.iso.org/obp/ui/\#iso:std:iso:6507:-1:ed-4:v1:en. Accessed 20 Jan 2018

35. Firm K, Boyer R, Welsch G (1994) Materials Properties Handbook: Titanium Alloys

36. Poondla N, Srivatsan TS, Patnaik A, Petraroli M (2009) A study of the microstructure and hardness of two titanium alloys: Commercially pure and Ti-6Al-4V. J Alloys Compd 486:162-167. https://doi.org/10.1016/j.jallcom.2009.06.172

37. Khodabakhshi F, Haghshenas M, Eskandari H, Koohbor B (2015) Hardness-strength relationships in fine and ultra-fine grained metals processed through constrained groove pressing. Mater Sci Eng A 636:331-339. https://doi.org/10.1016/j.msea.2015.03.122

38. Dieter GE, Bacon D, George Ellwood Dieter DB (1988) Mechanical Metallurgy

39. Fahad MK (1996) Stresses and failure in the diametral compression test. J Mater Sci 31:3723-3729. https://doi.org/10.1007/BF00352786

40. Procopio AT, Zavaliangos A, Cunningham JC (2003) Analysis of the diametrical compression test and the applicability to plastically deforming materials. J Mater Sci 38:3629-3639. https://doi.org/10.1023/A:1025681432260 